\title{
Dual role of acetaminophen in promoting hepatoma cell apoptosis and kidney fibroblast proliferation
}

\author{
YUNG-LUEN YU ${ }^{1,2,3^{*}}$, GIOU-TENG YIANG ${ }^{4,5^{*}}$, PEI-LUN CHOU ${ }^{6,7}$, HSU-HUNG TSENG $^{8}$, \\ TSAI-KUN WU ${ }^{2,9}$, YU-TING HUNG ${ }^{10}$, PEI-SHIUAN LIN ${ }^{10}$, SHU-YU LIN ${ }^{10}$, \\ HSIAO-CHUN LIU ${ }^{11}$, WEI-JUNG CHANG ${ }^{1}$ and CHYOU-WEI WEI ${ }^{10}$
}

\begin{abstract}
${ }^{1}$ Graduate Institute of Cancer Biology and Center for Molecular Medicine; ${ }^{2}$ The Ph.D. Program for Cancer Biology and Drug Discovery, China Medical University, Taichung 404; ${ }^{3}$ Department of Biotechnology, Asia University, Taichung 413;

${ }^{4}$ Department of Emergency Medicine, Taipei Tzu Chi Hospital, Buddhist Tzu Chi Medical Foundation, New Taipei 231;

${ }^{5}$ Department of Emergency Medicine, School of Medicine, Tzu Chi University, Hualien 970;

${ }^{6}$ Division of Allergy-Immunology-Rheumatology, Department of Internal Medicine, Saint Mary's Hospital Luodong,

Yilan 265; ${ }^{7}$ Department of Internal Medicine, School of Medicine, College of Medicine, Taipei Medical University,

Taipei $110 ;{ }^{8}$ Division of General Surgery, Taichung Hospital, Ministry of Health and Welfare, Taichung 403;

${ }^{9}$ Division of Renal Medicine, Tungs' Taichung Metroharbor Hospital, Taichung 435;

${ }^{10}$ Department of Nutrition, Master Program of Biomedical Nutrition, Hungkuang University, Taichung 433;

${ }^{11}$ Department of Nursing, Taipei Tzu Chi Hospital, Buddhist Tzu Chi Medical Foundation, New Taipei 231, Taiwan, R.O.C.
\end{abstract}

Received September 26, 2013; Accepted February 28, 2014

DOI: $10.3892 / \mathrm{mmr} .2014 .2085$

\begin{abstract}
Acetaminophen (APAP), is a safe analgesic and antipyretic drug at therapeutic dose, and is widely used in the clinic. However, high doses of APAP can induce hepatotoxicity and nephrotoxicity. Most studies have focused on high-dose APAP-induced acute liver and kidney injury. So far, few studies have investigated the effects of the therapeutic dose (1/10 of the high dose) or of the low dose (1/100 of the high dose) of APAP on the cells. The aim of this study was to investigate the cellular effects of therapeutic- or low-dose APAP treatment on hepatoma cells and kidney fibroblasts. As expected, high-dose APAP treatment inhibited while therapeutic and low-dose treatment did not inhibit cell survival of kidney tubular epithelial cells. In addition, therapeutic-dose treatment induced an increase in the $\mathrm{H}_{2} \mathrm{O}_{2}$ level, activated the caspase-9/-3 cascade, and induced cell apoptosis of hepatoma cells. Notably, APAP promoted fibroblast proliferation, even at low doses. This study demonstrates that different cellular effects are exerted upon treatment with different APAP
\end{abstract}

Correspondence to: Professor Chyou-Wei Wei, Department of Nutrition, Master Program of Biomedical Nutrition, Hungkuang University, No. 1018 Sec. 6 Taiwan Blvd., Shalu, Taichung 433, Taiwan, R.O.C.

E-mail: chyouweiwei@gmail.com

*Contributed equally

Key words: acetaminophen, kidney tubular cell, hepatoma, fibroblasts concentrations. Our results indicate that treatment with the therapeutic dose of APAP may exert an antitumor activity on hepatoma, while low-dose treatment may be harmful for patients with fibrosis, since it may cause proliferation of fibroblasts.

\section{Introduction}

Acetaminophen (APAP), also known as paracetamol, is a safe analgesic and antipyretic agent at therapeutic dose (1). It has been widely applied in the clinic (2-4). In general, an overdose of APAP of 10-15 g can cause serious toxicity and is harmful to the liver and the kidneys $(5,6)$. APAP is easily available and cheap, and thus patients may easily receive an overdose. This is one of the reasons that APAP constitutes the most common cause of self-poisoning in numerous countries (7-9). In order to study APAP overdose-induced liver and acute kidney damage, a number of animal and cell models have been established. Studies in these models have shown that treatment with high doses of APAP $(300-2,500 \mathrm{mg} / \mathrm{kg}$ ) can cause hepatotoxicity and nephrotoxicity in vivo (10-14), and doses $>0.005 \mathrm{~mol} / \mathrm{l}$ can induce cytotoxicity on kidney and liver cells (15-20). Previous studies have shown that APAP can induce apoptosis or necrosis on different cell models $(14,19,21)$, and that high-dose APAP treatment can increase oxidative stress, decrease the glutathione level and activate MAPK signaling pathways, resulting in cell cytotoxicity $(14,16,20,22-25)$.

A number of recent studies have indicated that high-dose APAP treatment causes liver and kidney failure (26-28). However, other studies reported that high-dose APAP treatment also exerts anticancer effects. These studies showed that APAP can induce cytotoxicity on neuroblastoma (SH-SY5Y 
cells), hepatoma (HuH7 cells) and breast cancer (FM3A cells) (29-33). These studies also demonstrated, in different tumor cell types, that APAP-induced cell death is related to the proteins NF- $\mathrm{KB}$, members of the Bcl-2 family, and the glycogen synthase kinase-3. In addition, APAP can enhance the chemotherapeutic anticancer effects of drugs used to treat neuroblastoma, leukemia and ovarian carcinoma $(30,34,35)$. According to the above studies, APAP can activate different cytotoxic mechanisms in liver, kidney and tumor cells $(14,19,21,31,36)$. To date, most studies have focused on the mechanisms of APAP-induced cytotoxicity and on how to prevent high-dose APAP-related poisoning of the liver and the kidneys. However, whether APAP can enhance cell proliferation remains unclear.

Kidney tubular epithelial cell damage can induce renal failure (37-40). Kidney fibrosis, via fibroblast proliferation, can also cause renal failure (41-43). Therefore, both kidney tubular cell damage and fibroblast proliferation can cause kidney dysfunction. Recently, high-dose APAP-induced nephrotoxicity was reported and investigated $(13,22,44-47)$. These studies found that high-dose APAP treatment can induce kidney tubular cell death in animal and cell models. In addition, numerous studies have demonstrated that high-dose APAP treatment can induce an increase in oxidative stress, causing tubular cell death through necrosis or the apoptotic pathway $(13,22,44,47,48)$. However, there is no evidence that APAP can cause kidney dysfunction by inducing fibroblast proliferation. The present study is the first to demonstrate, to the best of our knowledge, that high doses of APAP $(7.94 \mathrm{mM})$ can inhibit cell survival in kidney tubular cells (NRK-52E), while promoting cell proliferation in kidney interstitial fibroblasts (NRK-49F).

In addition, APAP can induce different cytotoxic mechanisms on different hepatoma cell lines. APAP can induce caspase-dependent apoptosis on hepatoma $\mathrm{HuH7}$ and SK-Hep1 cells $(31,49)$ and induces apoptosis and necrosis on hepatoma HepG2 cells (50). Additionally, a study demonstrated that high-dose APAP treatment can inhibit DOX-induced cell death in hepatoma HepG2 cells (36). Although APAP-induced apoptosis of hepatoma Hep3B cells was reported (51), the underlying mechanisms are still unclear.

\section{Materials and methods}

Materials. Luminol, lucigenin and Hoechst 33342 were purchased from Sigma-Aldrich (St. Louis, MO, USA). Transforming growth factor (TGF)- $\beta$ was purchased from R\&D Systems (Minneapolis, MN, USA). The MTT assay kit was purchased from Bio Basic Canada, Inc. (Markham, ON, Canada). The caspase-9 substrate acetyl-Leu-Glu-His-Asp-p-nitroanilide (Ac-LEHD-pNA), the caspase-3-like substrate acetyl-Asp-Glu-Val-Asp-p-nitroanilide (Ac-DEVD-pNA) and the caspase- 8 substrate acetyl-Ile-Glu-Thr-Asp- $p$-nitroanilide (Ac-IETD-pNA) were purchased from AnaSpec, Inc. (San Jose, CA, USA). Fetal bovine serum (FBS), Dulbecco's modified Eagle's medium (DMEM), non-essential amino acids, L-glutamine and penicillin/streptomycin were purchased from Gibco-BRL (Carlsbad, CA, USA).
Cell lines and cultures. The rat kidney cell lines NRK-52E (tubular epithelial cells) and NRK-49F (fibroblasts) and Hep3B cells were purchased from the Bioresource Collection and Research Center (Hsinchu, Taiwan). These cell lines were cultured in DMEM medium supplemented with $10 \%$ FBS, $2 \mathrm{mM}$ L-glutamine, $100 \mathrm{IU} / \mathrm{ml}$ penicillin/streptomycin and $0.1 \mathrm{mM}$ non-essential amino acids, and were maintained at $37^{\circ} \mathrm{C}$ in a humidified atmosphere containing $5 \% \mathrm{CO}_{2}$, as in $(52,53)$.

Cell survival assay. Survival rates of NRK-52E, NRK-49F and Hep3B cells were determined with the MTT assay as previously described $(54,55)$. Briefly, cells were cultured in 96-well plates. On the second day, cells were divided into the control and experimental groups. After cells were treated with $7.94 \mathrm{nM}$ APAP, 0.794 nM APAP, $0.0794 \mathrm{nM}$ APAP and 1nM TGF-B, respectively, cell survival rates were measured every day. The MTT assay was conducted daily according to the manufacturer's instructions. Absorbance was measured at $570 \mathrm{~nm}$ using a multi-well ELISA reader (Molecular Devices, Sunnyvale, CA, USA).

Quantification of $\mathrm{H}_{2} \mathrm{O}_{2}$ and $\mathrm{O}_{2}^{-}$levels. $\mathrm{H}_{2} \mathrm{O}_{2}$ and $\mathrm{O}_{2}^{-}$levels were measured using a lucigenin-amplified chemiluminescence method, as in $(56,57)$. Briefly, $200 \mu 1$ of cell lysate was mixed with $0.2 \mathrm{mmol} / \mathrm{l}$ of luminol solution $(100 \mu \mathrm{l})$ for the quantification of the $\mathrm{H}_{2} \mathrm{O}_{2}$ level, or with $0.1 \mathrm{mmol} / \mathrm{l}$ of lucigenin solution $(500 \mu \mathrm{l})$ for the quantification of the $\mathrm{O}_{2}^{-}$level. Measurements were then performed on the CLA-FSI chemiluminescence analyzing system (Tohoku Electronic Industrial Co., Ltd., Sendal, Japan). Each assay was performed four times and results were expressed as the chemiluminescence count per $10 \mathrm{sec}$.

Nuclear observation. Nuclear morphology was observed by nuclear staining with Hoechst 33342. Cells were treated with Hoechst $33342(10 \mu \mathrm{g} / \mathrm{ml})$ for $10 \mathrm{~min}$. Nuclear condensation and DNA fragmentation were observed under a fluorescence microscope (excitation, 352; emission, $450 \mathrm{~nm}$; Olympus BX61; Olympus Corporation, Tokyo, Japan), as described in previous studies $(58,59)$.

Caspase activity assay. Cells were treated with lysis buffer (50 mM Tris- $\mathrm{HCl}, 120 \mathrm{mM} \mathrm{NaCl}, 1 \mathrm{mM}$ EDTA, $1 \%$ NP-40, $\mathrm{pH}$ 7.5), and then $1 \mu \mathrm{M}$ protease inhibitors (Cocktail set 539131; Merck KGaA, Darmstadt, Germany) were added. Cell pellets were obtained by centrifugation $(15,000 \mathrm{x} \mathrm{g}$, $\left.4^{\circ} \mathrm{C}, 30 \mathrm{~min}\right)$. Caspase- $-3,-8$ and -9 activities were determined based on assays described in previous studies (60-62). Briefly, $40 \mu \mathrm{l}$ of cell lysate ( $80 \mu \mathrm{g}$ total protein) were mixed with $158 \mu 1$ reaction buffer ( $20 \%$ glycerol, $0.5 \mathrm{mM}$ EDTA, $5 \mathrm{mM}$ dithiothreitol, $100 \mathrm{mM}$ HEPES, $\mathrm{pH}$ 7.5) and $2 \mu \mathrm{l}$ fluorogenic substrate (Ac-LEHD-pNA, Ac-DEVD-pNA, or Ac-IETD-pNA) and were incubated at $37^{\circ} \mathrm{C}$ for $6 \mathrm{~h}$. The absorbance of the cleaved fluorogenic substrate was detected at $405 \mathrm{~nm}$ (A405) in a FLx800 ${ }^{\mathrm{TM}}$ fluorescence microplate reader (BioTek Instruments, Inc., Winooski, VT, USA). The fold increase (FI) in caspase activity was calculated using the following formula: $\mathrm{FI}=\left(\mathrm{A} 405_{\text {sample }}-\mathrm{A} 405_{\text {control }}\right) / \mathrm{A} 405_{\text {control }}$.

Data analysis. Data were obtained from four independent triplicate experiments and are presented as mean values of all data, with related standard deviations (SD). 
A

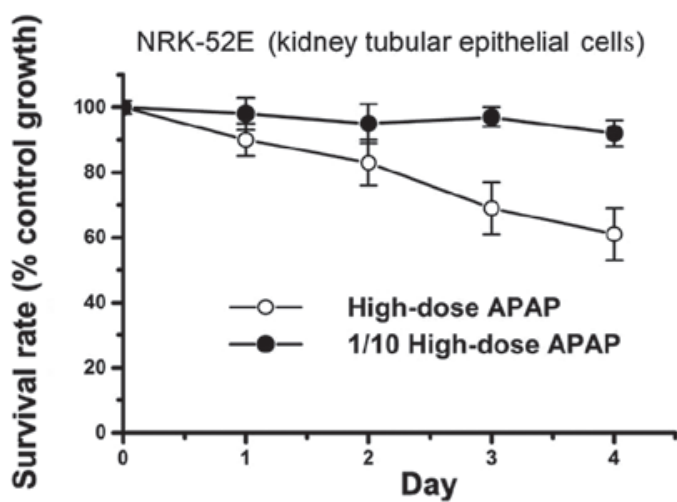

B

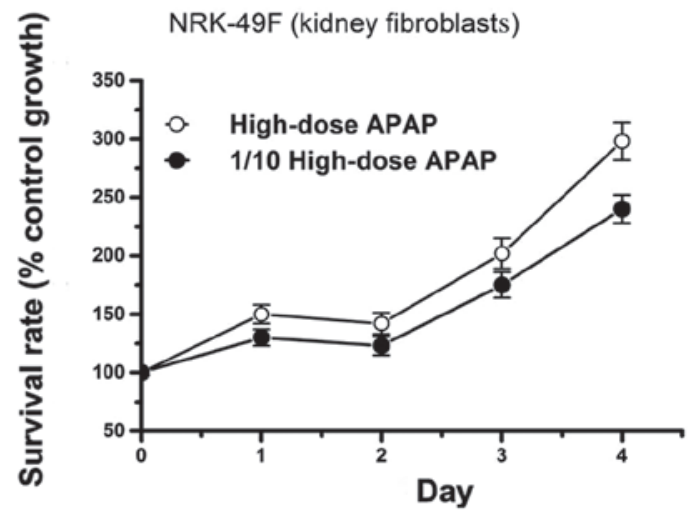

Figure 1. Effects of high-dose acetaminophen (APAP) treatment on the survival rates of the kidney cell lines (A) NRK-52E and (B) NRK-49F. Cells were treated with a high dose and 1/10 of the high dose of APAP. Survival rates were calculated daily using the MTT assay. Data are presented as mean \pm SD from four independent experiments.
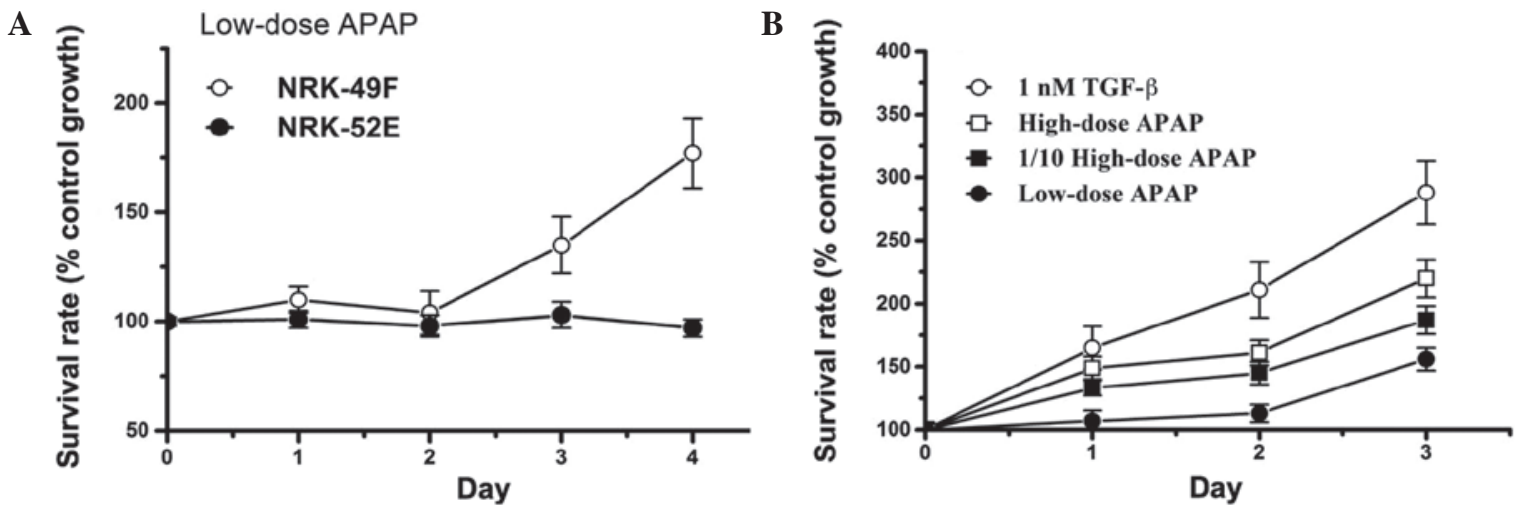

Figure 2. Effects of low-dose acetaminophen (APAP) treatment on kidney cell survival rates. Survival rates were calculated daily using the MTT assay. (A) NRK-49F and NRK-52E cells were treated with a low dose of APAP. (B) NRK-49F cells were treated with a high dose, 1/10 of the high dose and a low dose of APAP, as well as with the transforming growth factor (TGF) $-\beta$, as a positive control. Data are presented as mean \pm SD from four independent experiments.

\section{Results}

APAP treatment reduces the survival rate of kidney tubular epithelial cells, while inducing proliferation of kidney fibroblasts. Previous studies showed that a high dose of APAP $(>5 \mathrm{mM})$ can cause cell cytotoxicity in vitro (15-20). In accordance with these studies, we also found that high-dose $(7.94 \mathrm{mM})$ APAP treatment reduces the survival rate of kidney tubular epithelial cells (NRK-52E line), in a time-dependent manner (Fig. 1A). The survival rate of NRK-52E cells did not decrease upon treatment with $1 / 10$ of the high dose of APAP compared to high-dose treatment (Fig. 1A). These results suggest that APAP-induced cell cytotoxicity is dependent on APAP concentration and incubation time. However, to our surprise, although high-dose APAP treatment decreased the survival rate of NRK-52E cells, it promoted cell proliferation of kidney fibroblasts (NRK-49F line) (Fig. 1B). This was also observed upon treatment with $1 / 10$ of the high dose of APAP (Fig. 1B). It is well established in the clinic that both tubular epithelial cell damage and kidney fibrosis can induce renal fail ure $(13,22,41,43,47,48,63,64)$. Therefore, our findings indicate that APAP-induced renal failure may not only relate to the inhibition of tubular epithelial cell survival, but also to the promotion of renal fibroblast proliferation.
Low-dose APAP treatment induces proliferation of kidney fibroblasts. Previous studies have demonstrated that high-dose APAP treatment can inhibit tubular epithelial cell survival to induce renal failure $(13,22,43,47,48)$. In the present study, as shown in Fig. 1, high-dose APAP treatment inhibited growth of tubular epithelial cells, and induced proliferation of kidney fibroblasts. In patients with kidney fibrosis, it is important to prevent fibroblast proliferation, which further aggravates their condition. In order to enhance our understanding on the effects of APAP treatment on patients with fibrosis, it is therefore valuable to investigate whether low doses of APAP (below the therapeutic dose) can induce fibroblast proliferation. In this study, low-dose APAP treatment was applied on kidney fibroblasts to study its effects on cell growth. It is notable that low-dose APAP treatment did not inhibit cell survival of NRK-52E cells, while low-dose treatment induced cell proliferation in the fibroblast cell line NRK-49F (Fig. 2A). In addition, APAP induced fibroblast proliferation similarly to the treatment with the positive control TGF- $\beta$, and in a dose-dependent manner (Fig. 2B). APAP has not been reported to be toxic to liver and kidney cells at doses below the therapeutic dose in the clinic. However in our experiments, a low dose of APAP induced fibroblast proliferation, which may have harmful effects in patients with fibrosis. Thus, our 

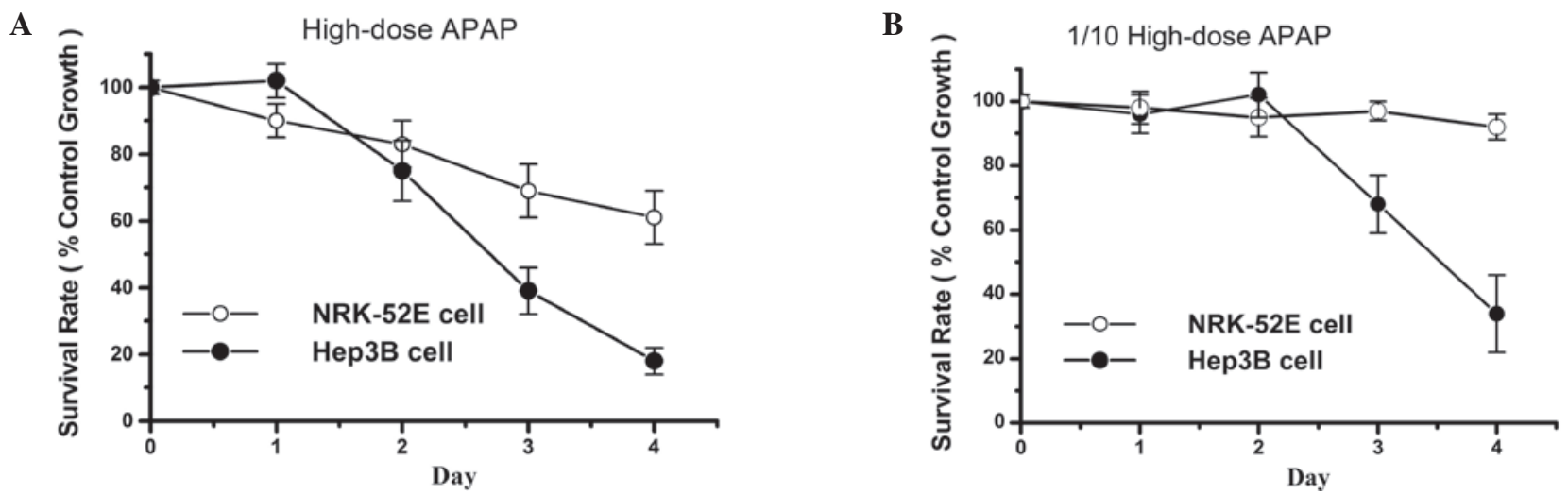

Figure 3. Effects of acetaminophen (APAP) on hepatoma cell survival rates. Survival rates were calculated daily using the MTT assay. (A) NRK-52E and Hep3B cells were treated with a high dose of APAP. (B) NRK-52E and Hep3B cells were treated with 1/10 of the high dose of APAP. Data are presented as mean \pm SD from four independent experiments.

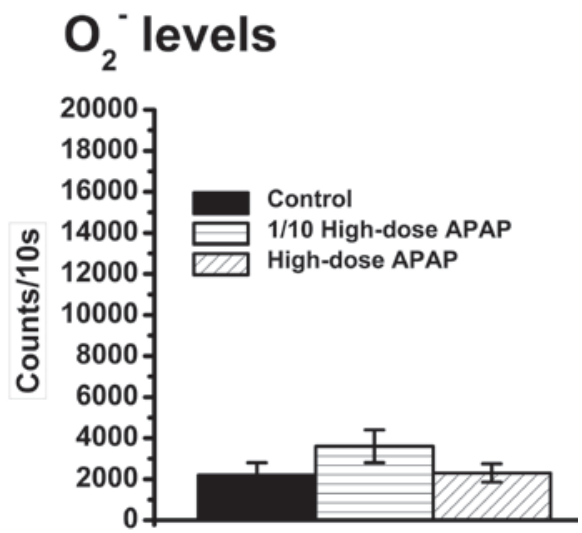

B

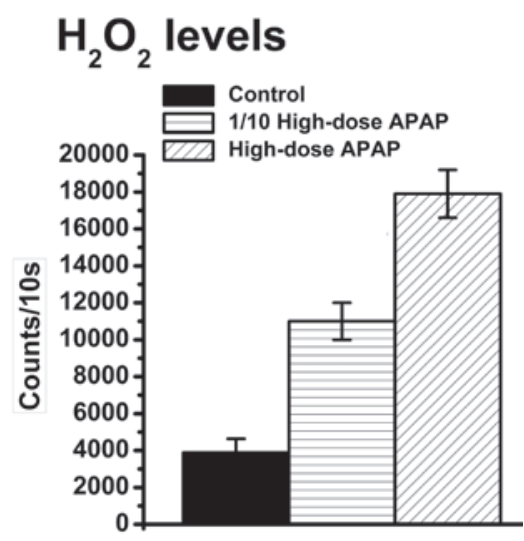

Figure 4. Effects of acetaminophen (APAP) on (A) $\mathrm{O}_{2}{ }^{-}$and (B) $\mathrm{H}_{2} \mathrm{O}_{2}$ levels in Hep3B cells. Measurements were performed following APAP treatment (6 h) using a lucigenin-amplified chemiluminescence method. Control (non-treated), high-dose APAP-treated and 1/10 high-dose APAP-treated cells were examined. Data are presented as mean \pm SD from four independent experiments.

study suggests that these patients may be sensitive to even low doses of APAP.

The cytotoxic effects of APAP are more prominent in Hep3B compared to NRK52 cells. High-dose APAP treatment induced cytotoxic effects not only in the tubular cell line NRK-52E, but also in the hepatoma cell line Hep3B (Fig. 3A). Cell survival rates of treated Hep3B cells were lower compared to those observed in NRK-52E cells. However, at an APAP concentration that was $1 / 10$ of the high dose (therapeutic dose), no obvious cytotoxic effects were observed in NRK-52E cells, while the survival rate of Hep3B cells was markedly reduced (Fig. 3B). Therefore, APAP exerts more prominent cytotoxic effects on Hep3B compared to NRK-52E cells. These results indicate that APAP, at a non-toxic concentration for healthy tubular cells, may exert an antitumor effect on hepatoma cells.

APAP treatment increases apoptosis of Hep3B cells via an increase in the $\mathrm{H}_{2} \mathrm{O}_{2}$ level. APAP-induced cytotoxic effects that relate to an increase in the generation of reactive oxygen species (ROS) were previously reported $(65,66)$. However, it is still unclear which ROS elements are increased upon APAP treatment. $\mathrm{O}_{2}{ }^{-}$and $\mathrm{H}_{2} \mathrm{O}_{2}$ are two commonly found ROS types in the cells. $\mathrm{O}_{2}{ }^{-}$and $\mathrm{H}_{2} \mathrm{O}_{2}$ levels were thus quantified following APAP treatment. The result showed that APAP causes an increase in the $\mathrm{H}_{2} \mathrm{O}_{2}$ (Fig. 4A), but not in the $\mathrm{O}_{2}^{-}$, level in Hep3B cells (Fig. 4B). Therefore, APAP-induced cytotoxicity is possibly related to $\mathrm{H}_{2} \mathrm{O}_{2}$ but not to $\mathrm{O}_{2}^{-}$. In addition, microscopic observations of the nuclear morphology revealed nuclear condensation and DNA fragmentation in the APAP-treated Hep3B cells (Fig. 5). These results overall suggest that APAP can induce cell cytotoxicity via an increase in the $\mathrm{H}_{2} \mathrm{O}_{2}$ level.

APAP activates the caspase-9/-3 cascade in Hep $3 B$ cells. Caspase activation can induce cell apoptosis $(60,61)$. In our study, APAP treatment also induced apoptosis of Hep3B cells, as indicated by results presented in Figs. 4 and 5. Therefore, caspase activities were next measured in Hep3B cells, focusing on the two major caspase cascades, the caspase-9/-3 and the caspase-8/-3, and using a substrate cleavage assay as previously described $(60,61)$. The caspase- 9 and -3 activities were found induced by treatment with $1 / 10$ of the high dose of APAP (Fig. 6A and C) However, the caspase-8 activity did not notably change upon APAP treatment (Fig. 6B). This result suggests that APAP can activate the caspase-9/-3 cascade to induce cell cytotoxicity in Hep3B cells. 

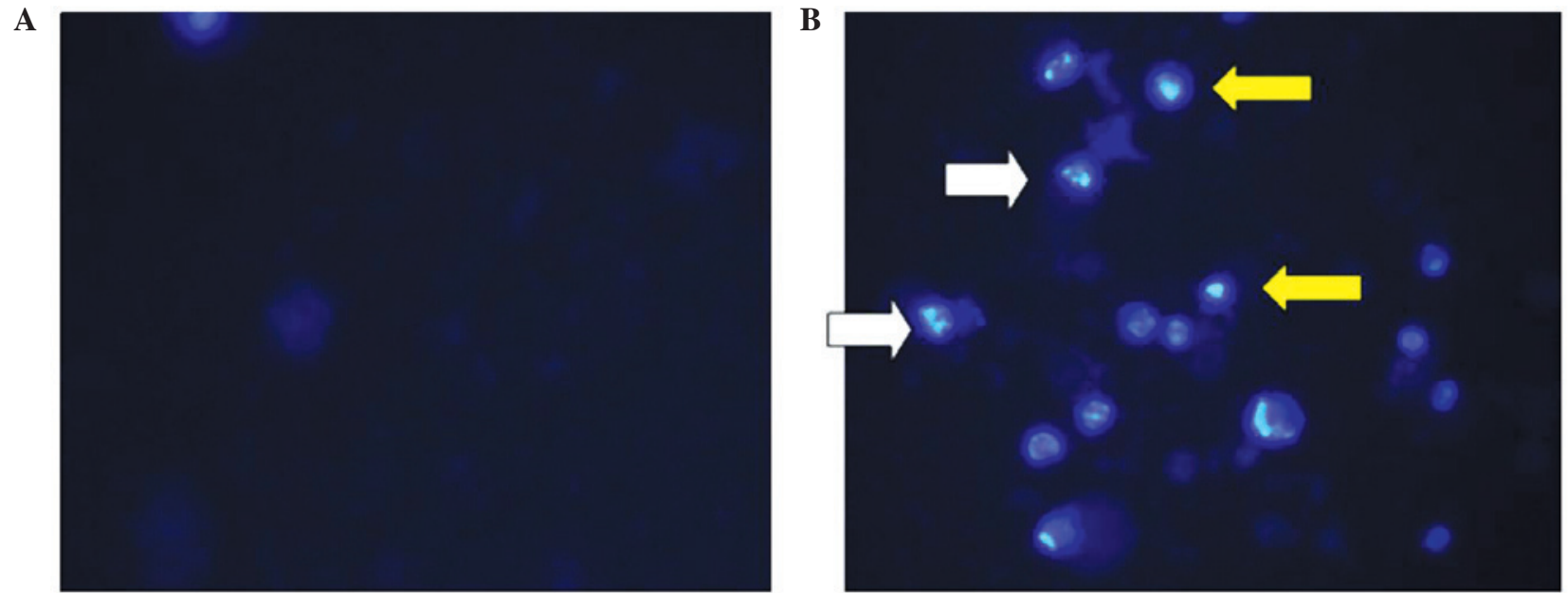

Figure 5. Effects of acetaminophen (APAP) treatment on nuclear condensation and DNA fragmentation. (A) Control (non-treated) and (B) APAP-treated Hep3B cells. Following cell treatment with APAP for 72 h, nuclear morphology was observed by nuclear staining with the Hoechst 33342 dye. Nuclear condensation (yellow arrows) and DNA fragmentation (white arrows) were observed on APAP-treated cells.

A
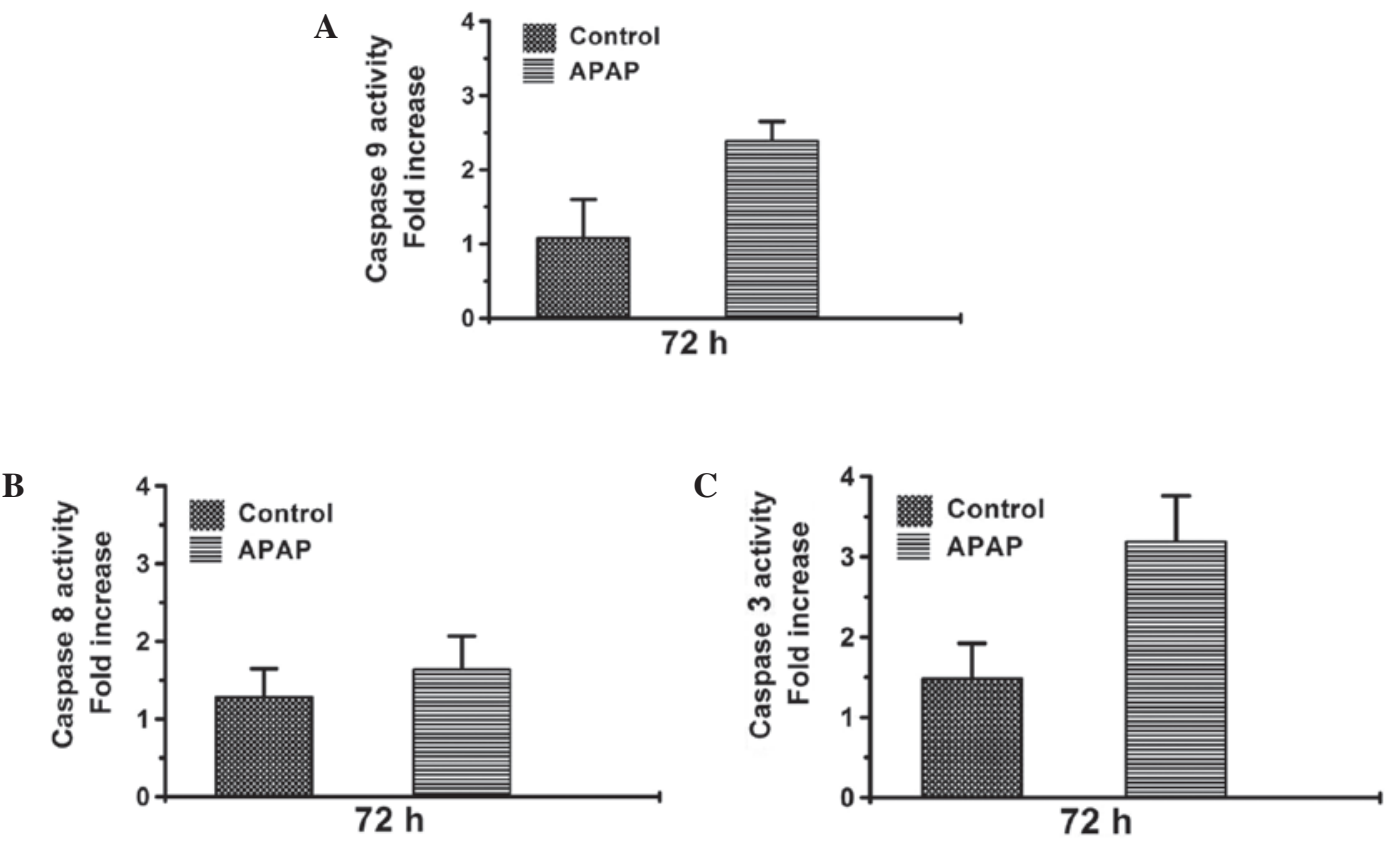

Figure 6. Activity of (A) Caspase-9; (B) caspase-8; and (C) caspase-3 activities in control (non-treated) and acetaminophen (APAP)-treated cells. Caspase-3 and -9 activities are increased in cells treated with $1 / 10$ of the high dose of APAP. Data are presented as mean \pm SD from three independent experiments.

\section{Discussion}

Both tubular epithelial cell damage and fibroblast proliferation can induce renal dysfunction $(13,22,41,43,47,48,63,64)$. Numerous studies have demonstrated that an APAP overdose can reduce tubular epithelial cell survival, resulting in nephrotoxicity $(13,22,43-46)$. Most of the studies to date have focused on high-dose APAP-induced acute intoxication of kidney tubular cells. These studies have highlighted the need to further investigate the effects of APAP and take these effects into consideration in order to prevent APAP-induced acute damage. However, it is still unclear whether low doses of APAP may cause chronic kidney damage. Our present study demonstrated that high-dose APAP treatment not only reduces survival of tubular epithelial cells, but it can also induce proliferation of fibroblasts, even at low doses. This implies that APAP-induced renal damage may occur through epithelial cell damage or fibroblast proliferation. In general, acute damage is easier to detect and diagnose compared to chronic damage; therefore, APAP overdose-induced acute intoxication is commonly observed, whereas low-dose APAP-induced damage is more likely to be ignored in the clinic. Here, we demonstrated that low-dose APAP treatment can promote fibroblast proliferation. Thus, we consider the therapeutic dose of APAP to be a safe analgesic and antipyretic agent for patients who do not show fibrosis, but potentially harmful to patients with kidney fibrosis.

The TGF- $\beta$ signaling pathway was shown to be involved in renal damage (67-69). TGF- $\beta$-induced renal damage 
has been associated with: i) tubular cell death $(68,70,71)$; ii) epithelial mesenchymal transition (72,73); and iii) fibroblast proliferation $(74,75)$. Up to now, no study has provided evidence that APAP can induce kidney fibroblast proliferation via TGF- $\beta$-related signals. In this study, NRK-49F cells (fibroblasts) treated with APAP showed a similar induction in proliferation to the one observed in the group treated with TGF- $\beta$. In addition, a previous study showed that TGF- $\beta$ is significantly elevated in APAP-treated liver tissue (71). Based on these observations, we hypothesize that APAP induces kidney fibroblast proliferation via the TGF- $\beta$ signaling pathway. Whether APAP also exerts effects on epithelial mesenchymal transition in kidney tubular cells warrants future investigation.

$\mathrm{O}_{2}{ }^{-}$and $\mathrm{H}_{2} \mathrm{O}_{2}$ are two commonly found ROS in the cells. They are typically produced by the electron transport chain. $\mathrm{O}_{2}$ can be removed from the cells through the enzymatic activity of superoxide dismutase, and $\mathrm{H}_{2} \mathrm{O}_{2}$ through the activity of catalase or glutathione. It is well established that cell damage occurs when $\mathrm{O}_{2}{ }^{-}$and $\mathrm{H}_{2} \mathrm{O}_{2}$ levels are increased. Previous studies showed that an APAP overdose can increase ROS levels and eventually, reduce cell viability $(51,76)$. However, these studies did not directly demonstrate which ROS element is increased upon APAP treatment. Here, two types of $\operatorname{ROS}\left(\mathrm{O}_{2}{ }^{-}\right.$and $\left.\mathrm{H}_{2} \mathrm{O}_{2}\right)$ were quantified following APAP treatment. The $\mathrm{H}_{2} \mathrm{O}_{2}$ level increased, but no notable change in the $\mathrm{O}_{2}{ }^{-}$level was observed in APAP-treated cells. Our study suggests that the inhibition of cell survival by APAP may occur through an increase in the $\mathrm{H}_{2} \mathrm{O}_{2}$ level. This is possibly the reason why $\mathrm{N}$-acetyl cysteine, a substrate for glutathione synthesis, is applied on patients with APAP-induced poisoning in emergency clinical cases $(77,78)$.

APAP-induced cell death has been extensively studied $(13,22,44,47,48)$. These studies demonstrated that APAP induces cell death either via the apoptotic or the necrotic death pathways in different cells. In our study, features of apoptosis were observed in APAP-treated Hep3B cells, similar to previous studies $(51,75)$. Moreover, our study further demonstrated that the caspase- $9 /-3$ cascade is activated upon APAP treatment, while the caspase- $8 /-3$ cascade is not. Caspase- $9 /-3$ signaling related to mitochondrial damage and caspase- $8 /-3$ signaling related to death receptor signals have been previously reported $(60,61)$. Thus, our data suggest that APAP-induced cell cytotoxicity might be associated with mitochondrial damage in Hep3B cells. Finally, previous studies have shown cytotoxicity upon high-dose $(>5 \mathrm{mM})$ APAP treatment in vitro (15-20). In this study, high-dose APAP treatment induced cytotoxicity in both healthy kidney tubular cells and hepatoma cells. However, $1 / 10$ of this dose was only cytotoxic to hepatoma cells. This suggests that non-toxic (to healthy cells) doses of APAP may be applied in the future as antitumor agents targeting cancer cells.

In summary, the present study shows that: i) APAP treatment can induce cell proliferation of kidney fibroblasts even at low doses, and thus we suggest that APAP treatment needs to be carefully monitored in patients with fibrosis; ii) APAP treatment can increase the $\mathrm{H}_{2} \mathrm{O}_{2}$ level and activate the caspase- $9 /-3$ cascade to cause cytotoxicity; and iii) the cytotoxic effects of APAP depend on the cell type, with hepatoma cells being more severely affected compared to healthy kidney tubular cells.

\section{Acknowledgements}

This study was supported by the following grants: NSC99-2320-B-039-030-MY3; NSC99-2632-B-039-001-MY3; NSC101-2321-B-039-004; NHRI-EX102-10245BI; TCRD-I101-04-03;TCRD-TPE-102-26; andTCRD-TPE-103-48.

\section{References}

1. Rumack BH: Acetaminophen misconceptions. Hepatology 40: 10-15, 2004.

2. Cuzzolin L, Antonucci R and Fanos V: Paracetamol (acetaminophen) efficacy and safety in the newborn. Curr Drug Metab 14: 178-185, 2013.

3. Klotz U: Paracetamol (acetaminophen) - a popular and widely used nonopioid analgesic. Arzneimittelforschung 62: 355-359, 2012.

4. Sullivan JE and Farrar HC; Section on Clinical Pharmacology and Therapeutics, Committee on Drugs: Fever and antipyretic use in children. Pediatrics 127: 580-587, 2011.

5. Young RJ: Dextropropoxyphene overdosage. Pharmacological considerations and clinical management. Drugs 26: 70-79, 1983.

6. Simkin S, Hawton K, Kapur N and Gunnell D: What can be done to reduce mortality from paracetamol overdoses? A patient interview study. QJM 105: 41-51, 2012.

7. Hawton K, Bergen H, Simkin S, et al: Impact of different pack sizes of paracetamol in the United Kingdom and Ireland on intentional overdoses: a comparative study. BMC Public Health 11: 460, 2011.

8. Hawton K, Townsend E, Deeks J, et al: Effects of legislation restricting pack sizes of paracetamol and salicylate on self poisoning in the United Kingdom: before and after study. BMJ 322: 1203-1207, 2001.

9. Daly FF, Fountain JS, Murray L, Graudins A and Buckley NA: Guidelines for the management of paracetamol poisoning in Australia and New Zealand - explanation and elaboration. A consensus statement from clinical toxicologists consulting to the Australasian poisons information centres. Med J Aust 188: 296-301, 2008.

10. Gopi KS, Reddy AG, Jyothi K and Kumar BA: Acetaminophen-in duced hepato- and nephrotoxicity and amelioration by silymarin and Terminalia chebula in rats. Toxicol Int 17: 64-66, 2010.

11. Abdel-Zaher AO, Abdel-Hady RH, Mahmoud MM and Farrag MM: The potential protective role of alpha-lipoic acid against acetaminophen-induced hepatic and renal damage. Toxicology 243: 261-270, 2008.

12. Cermik H, Taslipinar MY, Aydin I, et al: The relationship between $\mathrm{N}$-acetylcysteine, hyperbaric oxygen, and inflammation in a rat model of acetaminophen-induced nephrotoxicity. Inflammation 36: 1145-1152, 2013.

13. Ucar F, Taslipinar MY, Alp BF, et al: The effects of $\mathrm{N}$-acetylcysteine and ozone therapy on oxidative stress and inflammation in acetaminophen-induced nephrotoxicity model. Ren Fail 35: 640-647, 2013.

14. Liang YL, Zhang ZH, Liu XJ, et al: Melatonin protects against apoptosis-inducing factor (AIF)-dependent cell death during acetaminophen-induced acute liver failure. PLoS One 7: e51911, 2012.

15. Amaral SS, Oliveira AG, Marques PE, et al: Altered responsiveness to extracellular ATP enhances acetaminophen hepatotoxicity. Cell Commun Signal 11: 10, 2013.

16. Badmann A, Langsch S, Keogh A, Brunner T, Kaufmann T and Corazza N: TRAIL enhances paracetamol-induced liver sinusoidal endothelial cell death in a Bim- and Bid-dependent manner. Cell Death Dis 3: e447, 2012.

17. Badmann A, Keough A, Kaufmann T, Bouillet P, Brunner T and Corazza N: Role of TRAIL and the pro-apoptotic Bcl-2 homolog Bim in acetaminophen-induced liver damage. Cell Death Dis 2: e171, 2011.

18. McGill MR, Yan HM, Ramachandran A, Murray GJ, Rollins DE and Jaeschke H: HepaRG cells: a human model to study mechanisms of acetaminophen hepatotoxicity. Hepatology 53: 974-982, 2011.

19. Zhao X, Cong X, Zheng L, Xu L, Yin L and Peng J: Dioscin, a natural steroid saponin, shows remarkable protective effect against acetaminophen-induced liver damage in vitro and in vivo. Toxicol Lett 214: 69-80, 2012. 
20. Mobasher MA, Gonzalez-Rodriguez A, Santamaria B, et al: Protein tyrosine phosphatase 1B modulates GSK3beta/Nrf2 and IGFIR signaling pathways in acetaminophen-induced hepatotoxicity. Cell Death Dis 4: e626, 2013.

21. Ramachandran A, McGill MR, Xie Y, Ni HM, Ding WX and Jaeschke H: Receptor interacting protein kinase 3 is a critical early mediator of acetaminophen-induced hepatocyte necrosis in mice. Hepatology 58: 2099-2108, 2013

22. Ahmad ST, Arjumand W, Nafees S, et al: Hesperidin alleviates acetaminophen induced toxicity in Wistar rats by abrogation of oxidative stress, apoptosis and inflammation. Toxicol Lett 208: $149-161,2012$.

23. Inkielewicz-Stepniak I and Knap N: Effect of exposure to fluoride and acetaminophen on oxidative/nitrosative status of liver and kidney in male and female rats. Pharmacol Rep 64 902-911, 2012

24. Slitt AM, Dominick PK, Roberts JC and Cohen SD: Effect of ribose cysteine pretreatment on hepatic and renal acetaminophen metabolite formation and glutathione depletion. Basic Clin Pharmacol Toxicol 96: 487-494, 2005.

25. Yousef MI, Omar SA, El-Guendi MI and Abdelmegid LA: Potential protective effects of quercetin and curcumin on paracetamol-induced histological changes, oxidative stress, impaired liver and kidney functions and haematotoxicity in rat. Food Chem Toxicol 48: 3246-3261, 2010.

26. Zhang Y, Jia Y, Yang M, Yang P, Tian Y, Xiao A and Wen A The impaired disposition of probe drugs is due to both liver and kidney dysfunctions in $\mathrm{CCl}(4)$-model rats. Environ Toxicol Pharmacol 33: 453-458, 2012.

27. Zhao YL, Zhou GD, Yang HB, Wang JB, Shan LM, Li RS and Xiao XH: Rhein protects against acetaminophen-induced hepatic and renal toxicity. Food Chem Toxicol 49: 1705-1710, 2011.

28. Roomi MW, Kalinovsky T, Ivanov V, Rath M and Niedzwiecki A: A nutrient mixture prevents acetaminophen hepatic and renal toxicity in ICR mice. Hum Exp Toxicol 27: 223-230, 2008.

29. Posadas I, Santos P and Cena V: Acetaminophen induces human neuroblastoma cell death through NFKB activation. PLoS One 7 : e50160, 2012

30. Posadas I, Vellecco V, Santos P, Prieto-Lloret J and Cena V: Acetaminophen potentiates staurosporine-induced death in a human neuroblastoma cell line. Br J Pharmacol 150: 577-585, 2007

31. Jaeschke H: Comments on 'glycogen synthase kinase-3 mediates acetaminophen-induced apoptosis in human hepatoma cells' J Pharmacol Exp Ther 314: 1401-1404, 2005.

32. Macanas-Pirard P, Yaacob NS, Lee PC, Holder JC, Hinton RH and Kass GE: Glycogen synthase kinase-3 mediates acetaminophen-induced apoptosis in human hepatoma cells. J Pharmacol Exp Ther 313: 780-789, 2005.

33. Bilir A, Guneri AD and Altinoz MA: Acetaminophen and DMSO modulate growth and gemcitabine cytotoxicity in FM3A breast cancer cells in vitro. Neoplasma 51: 460-464, 2004.

34. Wu YJ, Neuwelt AJ, Muldoon LL and Neuwelt EA: Acetaminophen enhances cisplatin- and paclitaxel-mediated cytotoxicity to SKOV3 human ovarian carcinoma. Anticancer Res 33: 2391-2400, 2013.

35. Reszka KJ, Britigan LH, Rasmussen GT, Wagner BA, Burns CP and Britigan BE: Acetaminophen stimulates the peroxidative metabolism of anthracyclines. Arch Biochem Biophys 427: $16-29,2004$.

36. Manov I, Bashenko Y, Eliaz-Wolkowicz A, Mizrahi M, Liran O and Iancu TC: High-dose acetaminophen inhibits the lethal effect of doxorubicin in HepG2 cells: the role of P-glycoprotein and mitogen-activated protein kinase p44/42 pathway. J Pharmacol Exp Ther 322: 1013-1022, 2007.

37. Kidokoro K, Satoh M, Nagasu H, et al: Tacrolimus induces glomerular injury via endothelial dysfunction caused by reactive oxygen species and inflammatory change. Kidney Blood Press Res 35: 549-557, 2012

38. Stacchiotti A, Li Volti G, Lavazza A, et al: Different role of Schisandrin B on mercury-induced renal damage in vivo and in vitro. Toxicology 286: 48-57, 2011.

39. Suddek GM: Sunitinib improves chemotherapeutic efficacy and ameliorates cisplatin-induced nephrotoxicity in experimental animals. Cancer Chemother Pharmacol 67: 1035-1044, 2011

40. Neria F, Castilla MA, Sanchez RF, et al: Inhibition of JAK2 protects renal endothelial and epithelial cells from oxidative stress and cyclosporin A toxicity. Kidney Int 75: 227-234, 2009 .
41. Jang HS, Kim JI, Jung KJ, Kim J, Han KH and Park KM: Bone marrow-derived cells play a major role in kidney fibrosis via proliferation and differentiation in the infiltrated site. Biochim Biophys Acta 1832: 817-825, 2013.

42. Seikrit C, Henkel C, van Roeyen CR, et al: Biological responses to PDGF-AA versus PDGF-CC in renal fibroblasts. Nephrol Dial Transplant 28: 889-900, 2013.

43. Kim SH, Yu MA, Ryu ES, Jang YH and Kang DH: Indoxyl sulfate-induced epithelial-to-mesenchymal transition and apoptosis of renal tubular cells as novel mechanisms of progression of renal disease. Lab Invest 92: 488-498, 2012.

44. Abdul Hamid Z, Budin SB, Wen Jie N, Hamid A, Husain K and Mohamed J: Nephroprotective effects of Zingiber zerumbet Smith ethyl acetate extract against paracetamol-induced nephrotoxicity and oxidative stress in rats. J Zhejiang Univ Sci B 13: $176-185,2012$.

45. Chen N, Aleksa K, Woodland C, Rieder M and Koren G: The effect of $\mathrm{N}$-acetylcysteine on ifosfamide-induced nephrotoxicity: in vitro studies in renal tubular cells. Transl Res 150: 51-57, 2007.

46. Isik B, Bayrak R, Akcay A and Sogut S: Erdosteine against acetaminophen induced renal toxicity. Mol Cell Biochem 287: 185-191, 2006.

47. Lorz C, Justo P, Sanz A, Subira D, Egido J and Ortiz A: Paracetamol-induced renal tubular injury: a role for ER stress. J Am Soc Nephrol 15: 380-389, 2004.

48. Lorz C, Justo P, Sanz AB, Egido J and Ortiz A: Role of Bcl-xL in paracetamol-induced tubular epithelial cell death. Kidney Int 67: 592-601, 2005

49. Boulares AH, Zoltoski AJ, Stoica BA, Cuvillier O and Smulson ME: Acetaminophen induces a caspase-dependent and Bcl-XL sensitive apoptosis in human hepatoma cells and lymphocytes. Pharmacol Toxicol 90: 38-50, 2002.

50. Manov I, Hirsh M and Iancu TC: N-acetylcysteine does not protect HepG2 cells against acetaminophen-induced apoptosis. Basic Clin Pharmacol Toxicol 94: 213-225, 2004.

51. Manov I, Hirsh M and Iancu TC: Acetaminophen hepatotoxicity and mechanisms of its protection by $\mathrm{N}$-acetylcysteine: a study of Hep3B cells. Exp Toxicol Pathol 53: 489-500, 2002.

52. Wu CS, Yen CJ, Chou RH, et al: Cancer-associated carbohydrate antigens as potential biomarkers for hepatocellular carcinoma. PLoS One 7: e39466, 2012.

53. Yu YL, Su KJ, Chen CJ, et al: Synergistic anti-tumor activity of isochaihulactone and paclitaxel on human lung cancer cells. J Cell Physiol 227: 213-222, 2012.

54. Zhang L, Li J, Jiang Z, et al: Inhibition of aquaporin-1 expression by RNAi protects against aristolochic acid I-induced apoptosis in human proximal tubular epithelial (HK-2) cells. Biochem Biophys Res Commun 405: 68-73, 2011.

55. Yu YL, Chou RH, Wu CH, et al: Nuclear EGFR suppresses ribonuclease activity of polynucleotide phosphorylase through DNAPK-mediated phosphorylation at serine 776. J Biol Chem 287: 31015-31026, 2012.

56. Chen KH, Li PC, Lin WH, Chien CT and Low BH: Depression by a green tea extract of alcohol-induced oxidative stress and lipogenesis in rat liver. Biosci Biotechnol Biochem 75: 1668-1676, 2011.

57. Lin BR, Yu CJ, Chen WC, et al: Green tea extract supplement reduces D-galactosamine-induced acute liver injury by inhibition of apoptotic and proinflammatory signaling. J Biomed Sci 16: 35 , 2009.

58. Yu YL, Yu SL, Su KJ, et al: Extended O6-methylguanine methyltransferase promoter hypermethylation following n-butylidenephthalide combined with 1,3-bis(2-chloroethyl)-1-nitrosourea (BCNU) on inhibition of human hepatocellular carcinoma cell growth. J Agric Food Chem 58: 1630-1638, 2010

59. Yu YL, Wei CW, Chen YL, Chen MH and Yiang GT: Immunotherapy of breast cancer by single delivery with rAAV2-mediated interleukin-15 expression. Int J Oncol 36: 365-370, 2010.

60. Yiang GT, Chen YH, Chou PL, Chang WJ, Wei CW and $\mathrm{Yu}$ YL: The NS3 protease and helicase domains of Japanese encephalitis virus trigger cell death via caspase-dependent and -independent pathways. Mol Med Rep 7: 826-830, 2013

61. Yiang GT, Yu YL, Hu SC, Chen MH, Wang JJ and Wei CW: PKC and MEK pathways inhibit caspase-9/-3-mediated cytotoxicity in differentiated cells. FEBS Lett 582: 881-885, 2008

62. Wei CW, Lin CC, Yu YL, et al: n-Butylidenephthalide induced apoptosis in the A549 human lung adenocarcinoma cell line by coupled down-regulation of AP-2alpha and telomerase activity. Acta Pharmacol Sin 30: 1297-1306, 2009. 
63. Hassane S, Leonhard WN, van der Wal A, et al: Elevated TGFbeta-Smad signalling in experimental Pkd1 models and human patients with polycystic kidney disease. J Pathol 222: 21-31, 2010

64. Edward M, Quinn JA, Mukherjee S, et al: Gadodiamide contrast agent 'activates' fibroblasts: a possible cause of nephrogenic systemic fibrosis. J Pathol 214: 584-593, 2008.

65. Kumari A and Kakkar P: Lupeol protects against acetaminophen-induced oxidative stress and cell death in rat primary hepatocytes. Food Chem Toxicol 50: 1781-1789, 2012.

66. Anoush M, Eghbal MA, Fathiazad F, Hamzeiy H and Kouzehkonani NS: The protective effects of garlic extract against acetaminophen-induced oxidative stress and glutathione depletion. Pak J Biol Sci 12: 765-771, 2009.

67. Yao Y, Yang J, Wang D, et al: The aqueous extract of Lycopus lucidus Turcz ameliorates streptozotocin-induced diabetic renal damage via inhibiting TGF-betal signaling pathway. Phytomedicine 20: 1160-1167, 2013.

68. Hsieh TJ, Hsieh PC, Tsai YH, et al: Melamine induces human renal proximal tubular cell injury via transforming growth factor-beta and oxidative stress. Toxicol Sci 130: 17-32, 2012.

69. Hills CE, Siamantouras E, Smith SW, Cockwell P, Liu KK and Squires PE: TGF $\beta$ modulates cell-to-cell communication in early epithelial-to-mesenchymal transition. Diabetologia 55: 812-824, 2012.

70. Xu Y, Yang S, Huang J, Ruan S, Zheng Z and Lin J: Tgf- $\beta 1$ induces autophagy and promotes apoptosis in renal tubular epithelial cells. Int J Mol Med 29: 781-790, 2012.
71. Yoshikawa M, Hishikawa K, Idei M and Fujita T: Trichostatin a prevents TGF-beta1-induced apoptosis by inhibiting ERK activation in human renal tubular epithelial cells. Eur J Pharmacol 642: 28-36, 2010.

72. Li R, Wang Y, Liu Y, et al: Curcumin inhibits transforming growth factor- $\beta 1$-induced EMT via PPAR $\gamma$ pathway, not Smad pathway in renal tubular epithelial cells. PLoS One 8: e58848, 2013.

73. Han WQ,Zhu Q,Hu J,Li PL,Zhang F and Li N:Hypoxia-inducible factor prolyl-hydroxylase-2 mediates transforming growth factor beta 1-induced epithelial-mesenchymal transition in renal tubular cells. Biochim Biophys Acta 1833: 1454-1462, 2013.

74. Yan HD, Li XZ, Xie JM and Li M: Effects of advanced glycation end products on renal fibrosis and oxidative stress in cultured NRK-49F cells. Chin Med J (Engl) 120: 787-793, 2007.

75. Guo W, Xu H, Huang WY, et al: Prohibitin suppresses renal interstitial fibroblasts proliferation and phenotypic change induced by transforming growth factor-beta1. Zhonghua Yi Xue Za Zhi 87: 1660-1665, 2007 (In Chinese).

76. Levanon D, Manov I and Iancu TC: Qualitative and quantitative analysis of the effects of acetaminophen and $\mathrm{N}$-acetylcysteine on the surface morphology of Hep3B hepatoma cells in vitro. Ultrastruct Pathol 28: 3-14, 2004.

77. Williamson K, Wahl MS and Mycyk MB: Direct comparison of 20-hour IV, 36-hour oral, and 72-hour oral acetylcysteine for treatment of acute acetaminophen poisoning. Am J Ther 20: 37-40, 2013.

78. Saritas A, Kandis H, Baltaci D, et al: N-Acetyl cysteine and erdosteine treatment in acetaminophen-induced liver damage. Toxicol Ind Health: Oct 15, 2012 (Epub ahead of print). 